Results 868 notifications were received during the study period, 365 unique reports met our case definition. The rest were either duplicates, non-cases or unable to verify. The first 46 non-cases where a questionnaire was also completed were evaluated.

$18(39 \%)$ had no CSF sample or culture result, 15 (33\%) viral meningitis, $5(11 \%)$ UTI, 4 (9\%) sepsis, 3 (7\%) was contaminant and $1(2 \%)$ congenital hydrocephalus.

The median age (IOR) for the viral meningitis cases was 35.5 days (19-48), 10(67\%) were male. The reported presenting features were fever 14 (93\%), irritability 12 (80\%), poor feeding 10 (66\%), lethargy 8 (53\%), poor perfusion 7 (47\%), vomiting $2(15 \%)$ and comatose $1(7 \%)$.

The median (IOR) CSF white cell count and CSF protein for the viral meningitis cases was $334 / \mathrm{mm}^{3}(120-475)$ and $0.85 \mathrm{~g} / \mathrm{L}(0.59-$ 1.28) respectively.

Overall, two deaths were observed (one was a premature baby with multiple problems and the other died of Coxsackie meningitis). Conclusion We have been able to evaluate the clinical features of viral meningitis in this age group

Further analysis needs to be done to compare the viral meningitis with the bacterial cases.

\section{G142(P) USING A CHILD-FRIENDLY SURVEY TO OBTAIN FEEDBACK ABOUT THE HOSPITAL EXPERIENCE OF YOUNG INPATIENTS}

doi:10.1136/archdischild-2013-304107.154

A Tallett, B Hopwood. Children and Young People Resarch Team, Picker Institute Europe, Oxford, UK

\begin{abstract}
Aims The research aimed to obtain feedback from young hospital inpatients in a manner appropriate for their age and ability, to help NHS Trusts identify how they could make improvements in their paediatric services.

Methods A paediatric inpatient questionnaire was designed and piloted in 2010, focusing on the aspects of care that children and young people say are most important. The self-completion questionnaire is aimed at children (and their parents) aged 0-16 years, and is offered annually to NHS Trusts in England. 15 Trusts participated in the 2012 survey, which sampled patients discharged from hospital during February 2012. Questionnaires were posted to the home addresses of 850 patients/parents at each Trust, with two reminders being mailed to non-responders.
\end{abstract}

Results The overall response rate to the survey across all participating trusts was 34\% and demonstrated a high degree of child involvement and completion. Children and their parents reported room for improvement with the amount of privacy they were given in hospital, involvement in decisions and the quality of hospital food. In contrast, NHS Trusts performed well on hospital cleanliness and overnight facilities for parents. Children had a preference to stay on a ward with others of a similar age, whereas same-sex wards were less important. The survey also revealed some differences in the views of parents and children, for example children were less likely than parents to feel that the hospital ward was well suited to their age group. Conclusion The survey highlighted where there was most room for improving paediatric inpatient experience. The research demonstrated that children are willing and able to express their views and should be consulted about their healthcare experiences. For some question areas the views of children were shown to differ to that of parents. This emphasises the importance of speaking to children directly, and discourages using parent views alone as a basis for delivering care to children and young people.

\section{G143(P) IS THERE A CASE TO EMPHASISE THE USE OF LUSCOMBE FORMULA INSTEAD OF THE ADVANCED PAEDIATRIC LIFE SUPPORT COURSE FORMULA FOR THE PAEDIATRIC WEIGHT CALCULATION?}

doi:10.1136/archdischild-2013-304107.155
'A Kaniti, ${ }^{2} \mathrm{R}$ Thalava, ${ }^{1} \mathrm{R}$ Puttha. ${ }^{1}$ Paediatrics, University Hospitals of South Manchester, Manchester, UK; ${ }^{2}$ Orthopaedics, Tameside General Hospital NHS Foundation Trust, Manchester, UK; ${ }^{3}$ Paediatrics, University Hospitals of South Manchester, UK

Aim To validate Luscombe's formula (LF) for paediatric weight calculation comparing with the measured weight and the calculated weight by the Advanced Paediatric Life Support (APLS) formula and applying it to various emergency treatment doses.

Methodology The study was conducted by prospectively measuring the weight of all children attending our outpatient department, day unit and observation and assessment unit. The weight of children between the ages of 1 year to 10 years was included but any children with severe health problems and eating disorders were excluded from the study. The weights were calculated using both Luscombes weight formula and APLS formula and compared with the measured weight.

Results Out of a total of 156 children, 102 were between the ages of 1 to 10 years. 9 of them were excluded in view of chronic health problems of significance and 93 children were included in the study. The mean measured weight in this group was $17.27 \mathrm{kgs}$ while the mean of calculated weight by Luscombes formula was $18.89 \mathrm{kgs}$ and by APLS formula was $15.9 \mathrm{kgs}$, with the calculated means being within $10 \%$ deviation from the measured weight. The minimum measured weight was $8.45 \mathrm{kgs}$ and the maximum measured weight was $34.9 \mathrm{kgs}$. The minimum calculated weight by LF was $10 \mathrm{kgs}$ and the maximum was $34 \mathrm{kgs}$, while the minimum calculated weight by APLS formula was $10 \mathrm{kgs}$ and the maximum was $28 \mathrm{kgs}$ all of which were within the normal distribution.

If we apply all the three mean weights practically in resuscitation the dose of adrenaline $(1.7 \mathrm{ml}, 1.9 \mathrm{ml}$ and $1.6 \mathrm{ml}$ of 1 in 1000) and shock do not vary significantly, but there is variation in the dose of Intravenous fluid bolus $345 \mathrm{ml}, 378 \mathrm{ml}$ and $314 \mathrm{ml}$ and Intravenous ceftriaxone based on the means of the measured weight and calculated weights based on LF and APLS formula

Conclusion Both APLS formula and Luscombe formula provide guidance to calculate weight, in emergency to resuscitate the child with a difference of 7 to $10 \%$ from measured weight

\section{G144(P) A STUDY OF THE PATTERN OF ATTENDANCE AND PARENT SATISFACTION IN A PAEDIATRIC ASSESSMENT UNIT}

doi:10.1136/archdischild-2013-304107.156

'L Farrington, ${ }^{2} \mathrm{D}$ Mahmood. ' School of Medicine, University of Manchester, Manchester, UK; ${ }^{2}$ Paediatric Department, Royal Preston Hospital, Preston, UK

Aims In many UK hospitals, the Paediatric Assessment Unit (PAU) is part of the acute paediatric ward setting that receives acutely unwell children referred from a number of sources. This study aims to investigate the pattern of attendance to a PAU at a large District General hospital in the northwest and explores parents' satisfaction with the services provided, with the ultimate aim of improving the provision of such services.

Methods A retrospective study analysed patient admissions to the PAU, between August 2011 and May 2012, using data from an electronic database $(n=5456)$. In addition, a questionnaire was devised to measure parent satisfaction with the services offered. One hundred and nineteen parents who accompanied their children filled the questionnaire in the period between 21 $1^{\text {st }}$ May and $13^{\text {th }}$ June $2012(\mathrm{n}=119)$.

Results The mean age of children attending the PAU was 4.5 years. More children attended the PAU on weekdays than weekends, with Monday and Tuesday having the highest rates of attendance. The busiest times were from 17:00-22:00 hours. Despite a mean length of stay of 3.6 hours, parents were generally satisfied with this time $(62 \%)$. Almost all parents were satisfied with the level of care provided $(83.8 \%)$. Although the majority were also satisfied with the 